\title{
Effect of nitric oxide synthesis inhibition with nebulized L-NAME on ventilation-perfusion distributions in bronchial asthma
}

\author{
F.P. Gómez*, J.A. Barberà*, J. Roca*, R. Iglesia*, J. Ribas*, P.J. Barnes+, \\ R. Rodriguez-Roisin*
}

Effect of nitric oxide synthesis inhibition with nebulized L-NAME on ventilation-perfusion distributions in bronchial asthma. F.P. Gómez, J.A. Barberà, J. Roca, R. Iglesia, J. Ribas, P.J. Barnes, R. Rodriguez-Roisin. CERS Journals Ltd 1998.

ABSTRACT: Patients with clinically stable asthma may show ventilation-perfusion $\left(V^{\prime} \mathrm{A} / Q^{\prime}\right)$ mismatch. Nitric oxide (NO), a potent endogenous vasodilator, is increased in exhaled air of asthmatics. Such an increased NO production may be detrimental for optimal $V^{\prime} \mathrm{A} / Q^{\prime}$ balance owing to the potential inhibition of hypoxic pulmonary vasoconstriction. This study was undertaken to investigate the relationship between the concentration of $\mathrm{NO}$ in exhaled air and the degree of gas-exchange impairment and to assess the effect of nebulized $N^{\mathrm{G}}$-nitro-L-arginine methyl ester (L-NAME), a competitive inhibitor of NO synthesis, on gas exchange in patients with asthma.

Twelve patients (four females and eight males, aged $31 \pm 5 \mathrm{yrs}$ ) with clinically stable asthma (forced expiratory volume in one second (FEV1) 80 $55 \%$ ) not treated with glucocorticoids and increased exhaled NO $(58 \pm 9$ parts per billion (ppb)) were studied. Exhaled NO, respiratory system resistance $(R \mathrm{rs})$, arterial blood gases and $V^{\prime} \mathrm{A} / Q^{\prime}$ distributions were measured before and 30, 60,90 and $120 \mathrm{~min}$ after placebo or L-NAME (10. 1 M) nebulization; in eight patients pulmonary haemodynamics were also measured.

At baseline no relationships between exhaled NO and gas-exchange measurements were shown. Nebulized L-NAME induced a significant decrease in exhaled NO $(p<$ $0.001)$, which was maximal at $90 \mathrm{~min}(-55 \pm 5 \%)$. However, after $\mathrm{L}-\mathrm{NAME}$ no changes in $R \mathbf{r s}$, arterial oxygen tension, the alveolar-arterial pressure difference in oxygen or $V^{\prime} \mathrm{A} / Q^{\prime}$ distributions were shown and nebulized L-NAME did not modify pulmonary artery pressure.

In conclusion, the degree of gas-exchange impairment in stable asthma is not related to nitric oxide concentration in exhaled air and nitric oxide synthesis inhibition with $N^{\mathrm{G}}$-nitro-L-arginine methyl ester does not alter gas exchange or pulmonary haemodynamics, such that ventilation-perfusion disturbances do not appear to be related to an increased synthesis of nitric oxide in the airways. Eur Respir J 1998; 12: 865-871.
*Servei de Pneumologia i Al.lèrgia Respiratòria, Dept de Medicina, Institut d'Investigacions Biomèdiques August Pi i Sunyer Hospital Clínic, Universitat de Barcelona, Barcelona, Spain. +National Heart and Lung Institute, Imperial College School of Medicine, London, UK.

Correspondence: J.A. Barberà Servei de Pneumologia i Al.lèrgia Respiratòria

Hospital Clínic

Villarroel 170

08036 Barcelona

Spain

Fax: 34932275455

Keywords: Arginine analogues nitric oxide synthase inhibitors pulmonary catheterization pulmonary gas exchange

Received: February 261998

Accepted after revision June 161998

Supported by grants FIS 97/0143 and 1997 SGR00086 from the Comissionat per a Universitats i Recerca de la Generalitat de Catalunya and an educational grant from ASTRA-España. F.P. Gómez was supported by a Predoctoral Research Fellowship from the European Respiratory Society (1996).
Patients with clinically stable asthma may show some degree of ventilation-perfusion $\left(V^{\prime} \mathrm{A} / Q^{\prime}\right)$ mismatch despite having maximal airflow rates within the normal range [1]. This $V^{\prime} \mathrm{A} / Q^{\prime}$ mismatching is usually reflected by an increased dispersion of blood-flow distribution, which is a sensitive marker of units with reduced $V^{\prime} \mathrm{A} / Q^{\prime}$ ratio that result from peripheral airway narrowing secondary to bronchial inflammation, and are not necessarily reflected in spirometric measurements $[2,3]$.

Nitric oxide (NO) is a ubiquitous biological mediator synthesized by different cells within the respiratory system [4], which is involved in a variety of physiological and pathobiological mechanisms of respiratory disorders [5]. Different studies have shown an increased concentration of NO in the exhaled air of patients with bronchial asthma [6-8], probably reflecting the increased activity of the inducible isoform of NO synthase (iNOS) stimulated by airway inflammation [9]. Theoretically, such an increased production of endogenous NO may exert variable effects on gas exchange in asthmatic patients [10]. On the one hand, NO has the capacity to relax airway smooth muscle and oppose bronchoconstriction [11, 12], thus exerting a protective effect on $V^{\prime} \mathrm{A} / Q^{\prime}$ balance. On the other hand, the vascular effects of NO may be detrimental for optimal gas exchange. NO has a vasodilator effect on the bronchial circulation [13] that may enhance plasma exudation and oedema formation in the airway mucosa, hence promoting airway narrowing. Furthermore, NO administered exogenously can inhibit hypoxic pulmonary vasoconstriction (HPV) [14], an effect that may induce $V^{\prime} \mathrm{A} / Q^{\prime}$ imbalance whenever HPV contributes to match pulmonary blood flow to ventilation in alveolar units [15]. Indeed, in patients with chronic obstructive pulmonary disease (COPD), inhaled $\mathrm{NO}$ further worsens both $V^{\prime} \mathrm{A} / Q^{\prime}$ distributions and arterial oxygenation, as a result of the inhibition of hypoxic vasoconstriction [16].

The administration of NO synthesis inhibitors by inhalation ( $N^{\mathrm{G}}$-nitro-L-arginine methyl ester (L-NAME), $N^{\mathrm{G}_{-}}$ monomethyl-L-arginine (L-NMMA) and aminoguanidine) has been shown to reduce significantly NO in exhaled air 
$[9,17]$. However, in asthmatics nebulized L-NAME seems to exert no effect on airflow rates, cardiac frequency or systemic blood pressure [9].

If the increased production of NO in the airways of asthmatics is detrimental for optimal gas exchange the concentration of NO in exhaled air could be related to the underlying degree of $V^{\prime} \mathrm{A} / Q^{\prime}$ imbalance. Thus, the inhibition of NO synthesis with a locally administered competitive inhibitor could optimize $V^{\prime} \mathrm{A} / Q^{\prime}$ matching, hence improving gas exchange. Accordingly, the present study was undertaken to investigate the relationship between the concentration of exhaled NO and the degree of gas-exchange impairment and to evaluate the effects of local inhibition of NO synthesis with nebulized L-NAME on $V^{\prime} \mathrm{A} / Q^{\prime}$ relationships, in patients with clinically stable bronchial asthma. Furthermore, since the effects of NO synthesis inhibition with nebulized L-NAME on pulmonary circulation are unknown its effect on pulmonary haemodynamics was measured in a subset of this asthmatic population.

\section{Subjects and methods}

\section{Study population}

Twelve patients (four females and eight males), aged $31 \pm 5$ (mean \pm SEM) yrs, with mild-to-moderate asthma were recruited from the author's outpatient department for the study, which was approved by the Ethical Research Committee of the Hospital Clinic. All subjects gave informed written consent after the purpose, risks and potential benefits of the study were explained to them. Patients had no respiratory infection or exacerbation of asthma within the 6 weeks preceding the study. Mean forced expiratory volume in one second (FEV1) was $80 \pm 5 \%$ predicted. All subjects had either a positive bronchodilator response (mean

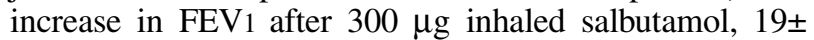
$3 \%)(\mathrm{n}=7)$ or a positive methacholine bronchial challenge (mean provocative dose of methacholine causing a fall $20 \%$ in FEV1 (PD20) from baseline, $0.40 \pm 0.18 \mu \mathrm{mol})(\mathrm{n}=5)$, and increased exhaled NO ( $>20$ parts per billion ( $\mathrm{ppb})$, the up-per $95 \%$ confidence limit of the control population [18]) (mean exhaled NO, 58 $\pm 9 \mathrm{ppb}$ ). No patient was under treat-ment with anti-inflammatory drugs (oral or inhaled glu-cocorticoids, disodium cromoglycate or nedocromil) and patients with any systemic or cardiopulmonary disease other than asthma were excluded. No attempt was made to separate atopic from nonatopic patients.

\section{Measurements}

Blood samples were collected anaerobically through a catheter inserted into the radial artery. Arterial oxygen tension $\left(\mathrm{Pa}_{\mathrm{a}} \mathrm{O}_{2}\right)$, carbon dioxide tension $\left(\mathrm{Pa}, \mathrm{CO}_{2}\right)$ and $\mathrm{pH}$ were analysed in duplicate with standard electrodes (Model 865; CIBA-Corning, Medfield, MA, USA). Haemoglobin concentration was measured with a co-oximeter (Model 865; CIBA-Corning). Minute ventilation and respiratory rate were recorded on a minute-by-minute basis with a calibrated Wright spirometer (MK8; BOC-Medical, Essex, UK). A low dead space, low resistance, nonrebreathing valve (Hans Rudolph, Kansas City, MO, USA) was used to collect the expired gas through a heated-mix- ing box. Oxygen uptake $\left(V^{\prime} \mathrm{O}_{2}\right)$ and $\mathrm{CO}_{2}$ production $(V$ ' $\mathrm{CO}_{2}$ ) were calculated from mixed expired $\mathrm{O}_{2}$ and $\mathrm{CO}_{2}$ concentrations (CPX System; Medical Graphics, St Paul, MN, USA). The alveolar-arterial oxygen tension difference $\left(P \mathrm{~A}-\mathrm{a}, \mathrm{O}_{2}\right)$ (normal val-ue $0.9 \mathrm{kPa}(ð 7 \mathrm{mmHg})$ [19]) was calculated according to the alveolar gas equation using the measured respiratory exchange ratio (RER). The total respiratory system resistance $(R \mathrm{rs})$ was measured by the forced os- cillation technique and its analysis restricted to $8 \mathrm{~Hz}$, as reported in detail elsewhere [20]. A three-lead electrocardiogram (ECG), cardiac frequency $(f \mathrm{R})$, systemic arterial pres-sure $(P \mathrm{~s})$ and arterial oxygen saturation $\left(\mathrm{Sa}_{\mathrm{a}} \mathrm{O}_{2}\right)$ through a pulse-oximeter (HP M1166A; Hewlett-Packard, Boblingen, Germany) were continuously recorded throughout the whole study (HP 7830A Monitor and HP 7754B Rec-order, Hewlett- Packard, Waltham, MA, USA).

In eight patients, on the day they were randomly assigned to receive L-NAME, a transvenous balloon-tipped Swan-Ganz catheter (Edwards Laboratories, Santa Ana, CA, USA) was placed into the pulmonary artery under pressure-wave monitoring (M1166A; Hewlett-Packard, Boeblingen, Germany). Intravascular pressures were continuously monitored, two measurements were performed at each time point of the study and the mean value was reported as the final result. Cardiac output $(Q \mathrm{~T})$ was determined either by thermodilution (M1012A; Hewlett-Packard) when the Swan-Ganz catheter had been inserted or otherwise by the dye dilution technique (DC-410; Waters Instruments, Rochester, MN, USA). Derived haemodynamic variables, namely pulmonary and systemic vascular resistance, were calculated using standard formulae.

$V^{\prime} \mathrm{A} / Q^{\prime}$ distributions were estimated with the multiple inert gas elimination technique [21]. In one patient $V^{\prime} \mathrm{A} / Q^{\prime}$ measurements were excluded for analysis because a technical problem in the inert gas infusion in one of the study days precluded its proper analysis.The dispersions of the two distributions on a logarithmic scale ( $\operatorname{LogSD} Q^{\prime}$ and $\operatorname{LogSD} V^{\prime}$, respectively) were used as indices of $V^{\prime} \mathrm{A} / Q^{\prime}$ mismatch (upper normal limit, 0.6 and 0.65 , respectively) [19]. In addition, as an overall descriptor of the combined dispersion of both blood flow and ventilation distributions, the difference among measured retentions and excretions of the inert gases corrected for the elimination of acetone (Disp R-E*, normal value $<3.0$ ) was used, which includes intrapulmonary shunt whenever it is present. Intrapulmonary shunt was defined as the fraction of cardiac output perfusing lung units with $V^{\prime} \mathrm{A} / Q^{\prime}$ ratios $<0.005$, normal $V^{\prime} \mathrm{A} / Q^{\prime}$ units were defined as those with $V^{\prime} \mathrm{A} / Q^{\prime}$ ratios between 0.1 and 10 and dead space was defined as the ventilation to units with $V^{\prime} \mathrm{A} / Q^{\prime}$ ratios $>100$. Exhaled NO was measured on a chemiluminescence analyser (CLD 700AL; EcoPhysics, Dürnten, Switzerland) using a single-breath manoeuvre, following the recommendations of the European Respiratory Society [22]. In brief, after flushing the analyser with NO-free air, patients were instructed to produce a slow vital capacity manoeuvre over $20-40 \mathrm{~s}$ into unobstructed tubing with a resistance to flow of $5 \mathrm{cmH}_{2} \mathrm{O}$, while $\mathrm{NO}$ and $\mathrm{CO}_{2}$ (CPX System; Medical Graphics) were sampled continuously through a side arm. Exhaled NO was calculated as the plateau concentration at the end of expiration, when $\mathrm{CO}_{2}$ reached its maximal level. The mean of at least two manoeuvres that differed by 
$<15 \%$ from each other was used to express exhaled NO at each specific time point.

\section{Study design}

A randomized, single-blind, placebo-controlled, crossover design was used. Asthma medication was withheld for at least $24 \mathrm{~h}$ before arrival at the laboratory. All patients were studied on two occasions, 3-6 days apart, in a semirecumbent position breathing room air. Both, placebo ( $2 \mathrm{~mL} 0.9 \%$ saline) and L-NAME (Sigma Chemical Co., St Louis, MO, USA) at a concentration of $10^{-1} \mathrm{M}(54 \mathrm{mg}$ in 2 $\mathrm{mL} 0.9 \%$ saline) were administered via a continu- ous flow nebulizer (Model CR01, Respiromed, Barcelona, Spain) over a 10-12 min period, through a mouthpiece and wearing a nose-clip. Measurements were performed at baseline and 30, 60, 90 and $120 \mathrm{~min}$ after ceasing the placebo/L-NAME nebulization. Maintenance of steady-state conditions was demonstrated by stability $( \pm 5 \%)$ of both ventilatory and haemodynamic variables, and by the close agreement between duplicate measurements of mixed expired and arterial $\mathrm{O}_{2}$ and $\mathrm{CO}_{2}$ (within $\pm 5 \%$ ).

\section{Statistical analysis}

The results are expressed as mean \pm SE. All analyses were performed with version 6.1.3 of the SPSS statistical package (SPSS, Chicago, IL, USA). Pearson's correlations were used to assess relationships between variables. Comparison of the effects of placebo and L-NAME was performed using a two-way repeated-measures analysis of variance (ANOVA). Significance was set at $p<0.05$ in all instances.

\section{Results}

\section{Baseline findings}

All patients showed high levels of exhaled NO. No differences between baseline levels of exhaled NO were shown in the two study days (table 1) and both measurements correlated closely $(\mathrm{r}=0.85, \mathrm{p}<0.001)$. Overall, the degree of gas-exchange impairment at baseline was mild, although measurements were within the spectrum of abnormalities described in patients with clinically stable asthma, from normal values to moderate impairment $\left(\mathrm{PA}-\mathrm{a}, \mathrm{O}_{2}\right.$ ranged $0.1-4.3 \mathrm{kPa}(0.9-32 \mathrm{mmHg})$ and the dispersion of bloodflow distribution $(\log \operatorname{SD} Q)$ from 0.36-0.91) (fig. 1). No significant differences between vehicle and L-NAME studies were shown at baseline in any of the measurements performed (table 1). Pulmonary haemodynamic measurements were within normal range in the eight patients who underwent right heart catheterization (table 2). No correlation was shown between the concentration of $\mathrm{NO}$ in exhaled air and gas-exchange measurements $\left(\mathrm{Pa}, \mathrm{O}_{2}, \mathrm{PA}-\mathrm{a}, \mathrm{O}_{2}\right.$ and indices of $V^{\prime} \mathrm{A} / Q^{\prime}$ inequality). Furthermore, exhaled NO was not correlated with $R \mathrm{rs}$, age or sex.

\section{Effects of L-NAME nebulization}

Both nebulizations with vehicle and L-NAME were clinically well tolerated and no patient noticed respiratory or other symptoms. Compared with placebo, L-NAME caused a significant reduction in exhaled NO in all patients $(\mathrm{p}<$ 0.001 ), which was maximal at $90 \mathrm{~min}$ (table 1, fig. 2). Such a decrease in exhaled NO was not accompanied by any change in $\mathrm{Pa}, \mathrm{O}_{2}, P \mathrm{~A}-\mathrm{a}, \mathrm{O}_{2}, V^{\prime} \mathrm{A} / Q^{\prime}$ relationships or $R \mathrm{rs}$, which remained unaltered during the whole period of study (table 1, fig. 1). Likewise, minute ventilation $(6.3 \pm$ $\left.0.5 \mathrm{~L} \cdot \mathrm{min}^{-1}\right), \mathrm{pH}(7.39 \pm 0.02), \mathrm{Pa}_{\mathrm{a}} \mathrm{CO}_{2}(5.1 \pm 0.1 \mathrm{kPa}(38 \pm 1$ $\mathrm{mmHg})), V^{\prime} \mathrm{O}_{2}\left(226 \pm 13 \mathrm{~mL} \cdot \mathrm{min}^{-1}\right)$, mixed venous oxygen tension $(5.4 \pm 0.1 \mathrm{kPa}(40.7 \pm 0.9 \mathrm{mmHg}))$, systemic arterial

Table 1. - Exhaled nitric oxide (NOex), respiratory system resistance ( $R \mathrm{rs}$ ) and gas exchange before and after nebulization with placebo or NG-nitro-L-arginine methyl ester (L-NAME)

\begin{tabular}{|c|c|c|c|c|c|c|c|}
\hline & & Baseline & $30 \mathrm{~min}$ & $60 \mathrm{~min}$ & $90 \mathrm{~min}$ & $120 \mathrm{~min}$ & p-value \\
\hline \multirow[t]{2}{*}{ NOex ppb } & Placebo & $56 \pm 11$ & $59 \pm 12$ & $56 \pm 11$ & $52 \pm 12 *$ & $50 \pm 10$ & \multirow{2}{*}{0.002} \\
\hline & L-NAME & $65 \pm 12$ & $35 \pm 6$ & $32 \pm 7$ & $30 \pm 6 *$ & $33 \pm 8^{*}$ & \\
\hline \multirow[t]{2}{*}{$R \mathrm{rs} \quad \mathrm{cmH}_{2} \mathrm{O} \cdot \mathrm{L}^{-1} \cdot \mathrm{s}$} & Placebo & $4.5 \pm 0.7$ & $4.5 \pm 0.6$ & $4.4 \pm 0.5$ & $4.2 \pm 0.5$ & $4.5 \pm 0.7$ & \multirow{2}{*}{0.77} \\
\hline & L-NAME & $4.5 \pm 0.7$ & $4.6 \pm 0.7$ & $4.5 \pm 0.6$ & $4.4 \pm 0.6$ & $4.6 \pm 0.7$ & \\
\hline \multirow[t]{2}{*}{$\mathrm{Pa}_{\mathrm{a}, \mathrm{O}_{2}} \mathrm{mmHg}$} & Placebo & $92 \pm 2$ & $94 \pm 3$ & $94 \pm 3$ & $94 \pm 3$ & $95 \pm 3$ & \multirow{2}{*}{0.81} \\
\hline & L-NAME & $92 \pm 3$ & $91 \pm 3$ & $93 \pm 3$ & $94 \pm 3$ & $95 \pm 4$ & \\
\hline \multirow[t]{2}{*}{$P \mathrm{~A}-\mathrm{a}, \mathrm{O}_{2} \mathrm{mmHg}$} & Placebo & $12 \pm 2$ & $10 \pm 3$ & $10 \pm 3$ & $10 \pm 3$ & $10 \pm 3$ & \multirow{2}{*}{0.94} \\
\hline & L-NAME & $12 \pm 3$ & $12 \pm 3$ & $10 \pm 3$ & $10 \pm 2$ & $10 \pm 3$ & \\
\hline \multirow[t]{2}{*}{ Shunt $\%$ of $\mathrm{CO}$} & Placebo & $0.4 \pm 0.3$ & $0.4 \pm 0.3$ & $0.3 \pm 0.3$ & $0.2 \pm 0.2$ & $0.2 \pm 0.2$ & \multirow{2}{*}{0.26} \\
\hline & L-NAME & $0.1 \pm 0.1$ & $0.4 \pm 0.3$ & $0.4 \pm 0.3$ & $0.4 \pm 0.2$ & $0.2 \pm 0.1$ & \\
\hline \multirow[t]{2}{*}{$\log D D Q^{\prime}$} & Placebo & $0.53 \pm 0.05$ & $0.52 \pm 0.06$ & $0.48 \pm 0.05$ & $0.48 \pm 0.06$ & $0.50 \pm 0.05$ & \multirow{2}{*}{0.59} \\
\hline & L-NAME & $0.53 \pm 0.05$ & $0.55 \pm 0.07$ & $0.52 \pm 0.06$ & $0.51 \pm 0.05$ & $0.54 \pm 0.05$ & \\
\hline \multirow[t]{2}{*}{$\operatorname{LogSD} V^{\prime}$} & Placebo & $0.64 \pm 0.07$ & $0.59 \pm 0.07$ & $0.56 \pm 0.08$ & $0.54 \pm 0.08$ & $0.56 \pm 0.07$ & \multirow{2}{*}{0.76} \\
\hline & L-NAME & $0.62 \pm 0.06$ & $0.60 \pm 0.07$ & $0.56 \pm 0.05$ & $0.58 \pm 0.07$ & $0.57 \pm 0.05$ & \\
\hline \multirow[t]{2}{*}{$\operatorname{Disp} R-E^{*}$} & Placebo & $4.8 \pm 0.9$ & $4.6 \pm 0.9$ & $4.2 \pm 0.9$ & $3.9 \pm 1.0$ & $4.0 \pm 0.8$ & \multirow{2}{*}{0.25} \\
\hline & L-NAME & $4.3 \pm 0.6$ & $4.5 \pm 0.7$ & $3.8 \pm 0.6$ & $4.3 \pm 0.8$ & $4.1 \pm 0.7$ & \\
\hline
\end{tabular}

Values are mean \pm SEM. ppb: parts per billion; $P \mathrm{a}, \mathrm{O}_{2}:$ arterial oxygen tension; $P \mathrm{~A}-\mathrm{a}, \mathrm{O}_{2}$ : alveolar-arterial pressure difference in oxygen. $\mathrm{CO}$ : cardiac output; shunt: \% of CO to lung units with ventilation-perfusion ratios $\left(V^{\prime} \mathrm{A} / Q^{\prime}\right)<0.005$; $\log$ sD $Q^{\prime}$ : dispersion of blood flow distribution; LogSD $V^{\prime}$ : dispersion of ventilation distribution; Disp $R-E^{*}$ : dispersion of retention minus excretion inert gases corrected for dead space. : significance of the effects of L-NAME calculated using a two-way repeated-measures analysis of variance. $\neq: \mathrm{n}=11$. *: $\mathrm{p}<0.05$ for the comparison with placebo (contrast test). $(1 \mathrm{mmHg}=0.133 \mathrm{kPa}$.) 

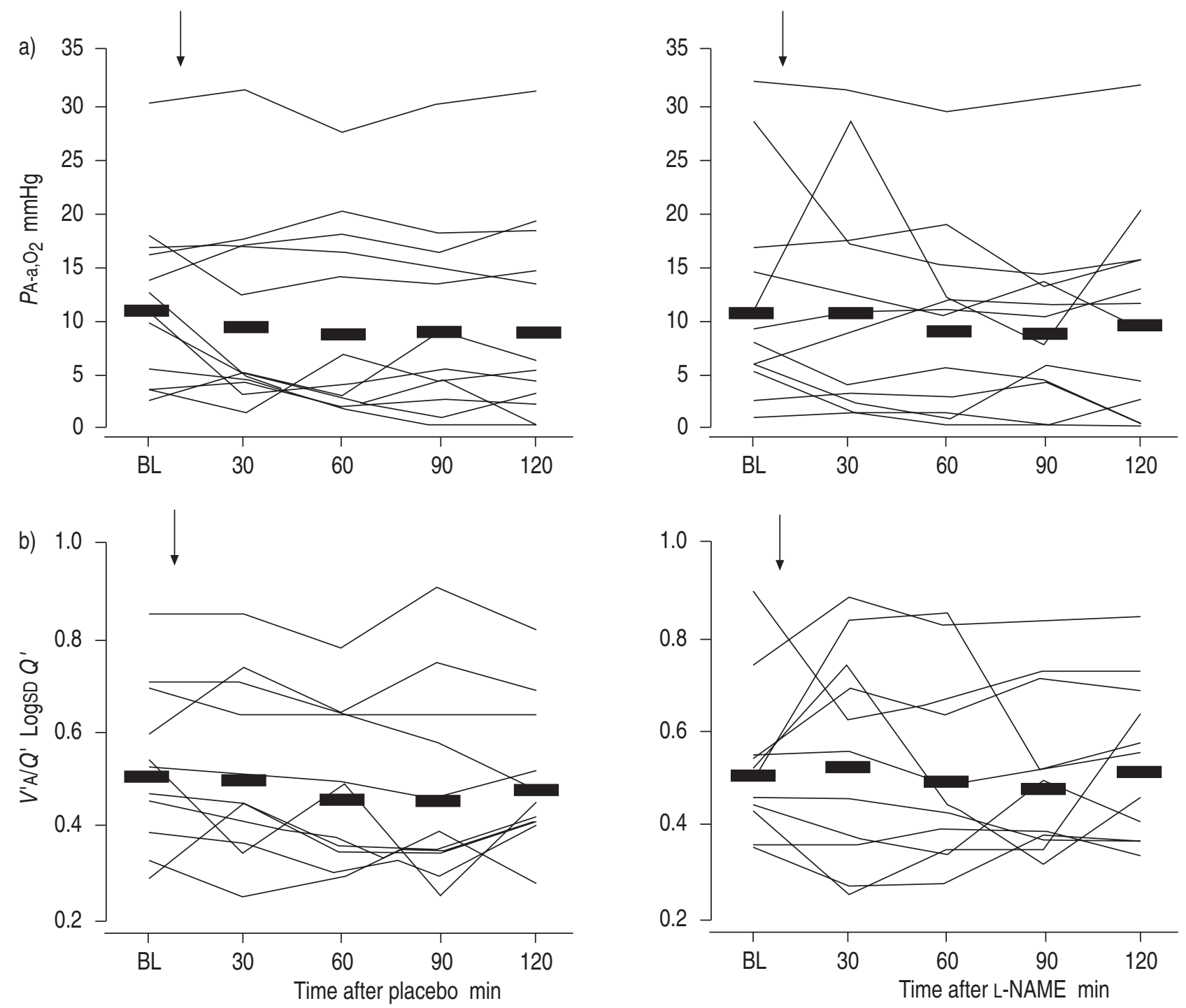

Fig. 1. - Individual time courses of a) alveolar-arterial pressure difference in oxygen $\left(P \mathrm{~A}-\mathrm{a}, \mathrm{O}_{2}\right)$ and b) ventilation-perfusion mismatch $\left(V^{\prime} \mathrm{A} / Q^{\prime}\right)$ (expressed as the dispersion of blood-flow distribution $\left(\operatorname{LogsD} Q^{\prime}\right)$, dimensionless) at baseline (BL) and after (arrows) nebulized placebo (left panels) or $N^{\mathrm{G}}$-nitro-L-arginine methyl ester (L-NAME) (right panels). $\quad$ : mean values. $(1 \mathrm{mmHg}=0.133 \mathrm{kPa}$.)

pressure and cardiac output (table 2) were not altered by L-NAME. Neither pulmonary artery pressure nor vascular resistance was increased by L-NAME (table 2, fig. 3). However, there was an unexpected, slight reduction in pulmonary artery pressure $30 \mathrm{~min}$ after L-NAME nebulization, which just reached statistical significance, but without physiological relevance (table 2 , fig. 3 ).

\section{Discussion}

The present study shows that the increased concentration of NO in exhaled air in patients with clinically stable asthma is not related to gas-exchange abnormalities and that the local inhibition of NO synthesis with nebulized L-NAME does not modify the gas-exchange status.

Exhaled NO is increased in some conditions of chronic inflammation of the airways, such as bronchial asthma [68] and bronchiectasis [23]. In asthmatics, exhaled NO increases in the late phase of the allergic reaction [24] and decreases 48-72 $\mathrm{h}$ after starting treatment with systemic glucocorticoids, a decrease that is associated with a parallel improvement in airflow rates [17, 25]. However, no relationship has been found between exhaled $\mathrm{NO}$ and measurements of respiratory function [22]. In the present study, conducted in clinically stable patients with mild-tomoderate asthma, no relationship could be found between exhaled NO levels and arterial blood gases or indices of $V^{\prime} \mathrm{A} / Q^{\prime}$ mismatch, or Rrs measured by the forced oscillation technique. Overall, these results indicate that the increased concentration of NO in exhaled air seems to be a marker of increased inflammatory activity within the airways rather than a pathobiological mediator with measurable activity. Furthermore, the results support the view that measurements of exhaled NO are useful in distinguishing populations (i.e. asthmatics) and in the follow-up of individual cases, but that they do not reflect differences in the severity of functional impairment between individuals [26]. 
Table 2. - Systemic and pulmonary haemodynamic values before and after NG-nitro-L-arginine methyl ester (L-NAME)

\begin{tabular}{lcccccc}
\hline & Baseline & $30 \mathrm{~min}$ & $60 \mathrm{~min}$ & $90 \mathrm{~min}$ & $120 \mathrm{~min}$ & $\mathrm{p}$-value \\
\hline$P_{\mathrm{s} \mathrm{mmHg}}$ & $89 \pm 2$ & $88 \pm 2$ & $88 \pm 2$ & $89 \pm 1$ & $89 \pm 2$ & 0.35 \\
$f \mathrm{C} \mathrm{min}-1$ & $72 \pm 3$ & $72 \pm 3$ & $72 \pm 3$ & $71 \pm 4$ & $73 \pm 4$ & 0.96 \\
$\mathrm{CO} \mathrm{L} \cdot \mathrm{min}^{-1}$ & $5.35 \pm 0.91$ & $5.55 \pm 1.05$ & $5.51 \pm 0.96$ & $5.66 \pm 1.16$ & $5.64 \pm 1.11$ & 0.29 \\
$P$ pa mmHg & $10 \pm 1$ & $9 \pm 1^{*}$ & $10 \pm 1$ & $10 \pm 1$ & $10 \pm 1$ & 0.05 \\
$P$ pao $\mathrm{mmHg}$ & $4 \pm 1$ & $4 \pm 1$ & $5 \pm 1$ & $5 \pm 1$ & $5 \pm 1$ & 0.34 \\
SVR dyn $\cdot \mathrm{s} \cdot \mathrm{cm}^{-5}$ & $1304 \pm 68$ & $1286 \pm 62$ & $1289 \pm 54$ & $1276 \pm 43$ & $1264 \pm 70$ & 0.67 \\
PVR dyn $\cdot \mathrm{s}^{-} \mathrm{cm}^{-5}$ & $92 \pm 8$ & $71 \pm 8$ & $74 \pm 10$ & $74 \pm 9$ & $72 \pm 6$ & 0.08 \\
\hline
\end{tabular}

Values are mean \pm sem. $P$ s: mean systemic arterial pressure; $f$ C: cardiac frequency; CO: cardiac output; $P$ pa: mean pulmonary artery pressure; $P$ pao: pulmonary artery occluded pressure; SVR: systemic vascular resistance; PVR: pulmonary vascular resistance. $t:$ significance of the effects of L-NAME calculated using a repeated-measures analysis of variance. *: $\mathrm{p}<0.05$ for the comparison with baseline (contrast test).

HPV is a complex pathophysiological phenomenon intended to match perfusion to ventilation within the lung, a mechanism considered to be very efficient in patients with bronchial asthma [15]. Indeed, in patients with different categories of asthma it has been shown that nifedipine [27] and 100\% oxygen breathing [28] may reverse HPV, hence deteriorating pulmonary gas exchange. The hypothesis was tested that endogenous NO may oppose HPV, entailing the potential of worsening gas exchange. This hypothesis arises from different lines of evidence. Firstly, in vitro studies in pulmonary artery rings have shown that endothelium-derived NO modulates the increase in tone induced by hypoxic stimuli $[29,30]$. Secondly, in healthy individuals inhaled NO inhibits the increase in pulmonary artery pressure induced by hypoxia [14], a feature that in COPD worsens pulmonary gas exchange [16]. Finally, it has been shown that in experimental models of lung injury endogenous NO opposes HPV and further deteriorates hypoxaemia by maintaining blood flow to poorly oxygenated alveolar units [31, 32]. At variance with these observations, in the present study local inhibition of NO synthesis with nebulized L-NAME did not exert any significant effect on arterial blood gas measurements and $V^{\prime} \mathrm{A} / Q^{\prime}$ relationships, reinforcing the view that the increased NO synthesis in asthma does not appear to be detrimental to gas exchange.
It has been suggested that endogenous NO may have protective effects in asthmatics. This is supported by observations showing that the inhibition of NO synthesis with L-NMMA promoted the bronchoconstriction induced by bradykinin [33] and by the finding that an increase in exhaled NO after rhinovirus infection was associated with a lower reactivity to histamine [12]. However, in the present group of patients with clinically stable asthma no change in Rrs was noticed after L-NAME administration, despite a significant drop in exhaled NO concentration. This suggests a marginal effect of augmented endogenous NO on the basal airway tone, in agreement with the data presented by YATES et al. [9]. Furthermore, after L-NAME administration no changes in $V^{\prime} \mathrm{A} / Q^{\prime}$ distributions, as measured by the inert gas technique [21], were noticed. Since the latter measurements appear to be more sensitive to changes in peripheral airways, it seems unlikely that endogenous NO exerts any significant effect on airway function in patients with stable asthma.

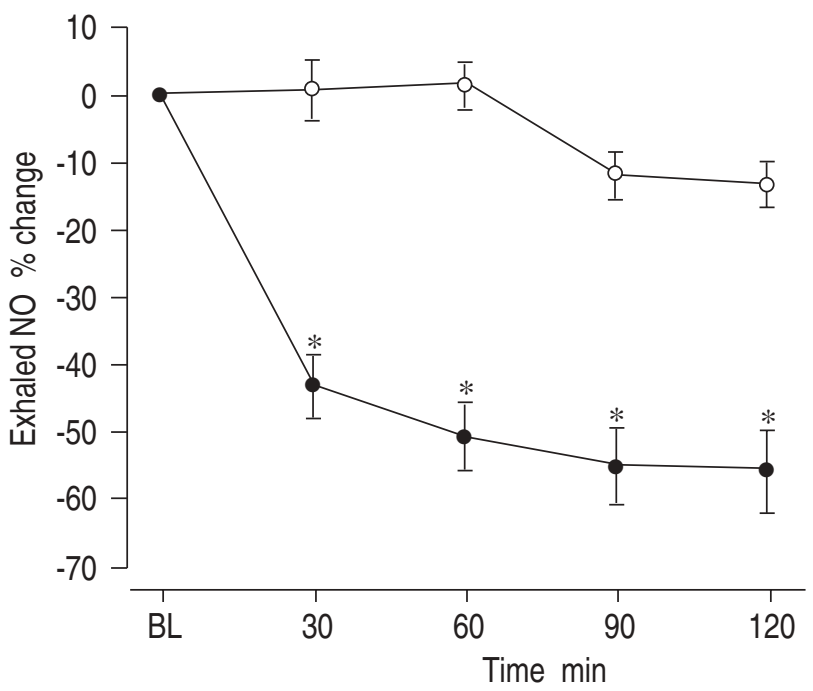

Fig. 2. - Exhaled nitric oxide (NO), expressed as percentage of change from baseline (BL), after either nebulized placebo $(O)$ or $N^{\mathrm{G}}$-nitro-Larginine methyl ester (L-NAME; $\bullet$ ). Values are mean士sEM. *: $\mathrm{p}<0.05$ compared with BL. 
Different reasons may account for the lack of effect of L-NAME. Firstly, the increased synthesis of NO in the airways, in the range of 0.1 parts per million (ppm), may not be sufficiently active to exert in this group of patients a significant effect on either airway or the vascular tone and, hence, on gas exchange. Indeed, the detrimental effect of NO on gas exchange, when given by inhalation, has been shown at concentrations of $40 \mathrm{ppm}$ [16], that is about 400 times greater than those observed in the exhaled air of asthmatics. Therefore, it cannot be excluded that higher concentrations of NO in the airways could be detrimental for optimal $V^{\prime} \mathrm{A} / Q^{\prime}$ matching and exert a different effect on gas exchange. Alternatively, L-NAME could have been ineffective because the underlying $V^{\prime} \mathrm{A} / Q^{\prime}$ imbalance was only mildly to moderately disturbed compared with previously reported observations $[1,27]$. In the present study it was not possible to look at more severe patients as they were receiving glucocorticoid treatment. Therefore, it might be speculated that L-NAME could exert a more active effect if basal $V^{\prime} \mathrm{A} / Q^{\prime}$ mismatch were more severely altered. Similarly, the lack of effect of nebulized L-NAME on gas exchange could be potentially explained by an insufficient delivery of the drug in peripheral airways, the most critical in terms of gas exchange. Accordingly, the reduction in exhaled air after L-NAME nebulization can be explained by its preferential deposition in large airways, whereas in peripheral airways it did not exert any significant effect because it did not reach a sufficient dose of deposition. This is not thought to be the case since the nebulizer used delivers particles in the range of $2-5 \mu \mathrm{m}$ in diameter, which should reach in a significant proportion peripheral airways [34]. None the less, it cannot be excluded that the dose used was insufficient to influence gas exchange. The dose of L-NAME administered was the same as that used in a previous study [9]. However, this dosage was established empirically, since there is no information on doseresponse studies with nebulized L-NAME that would help to define the most efficient dosage of the drug. Accordingly, a greater dosage of L-NAME may have exerted a different effect.

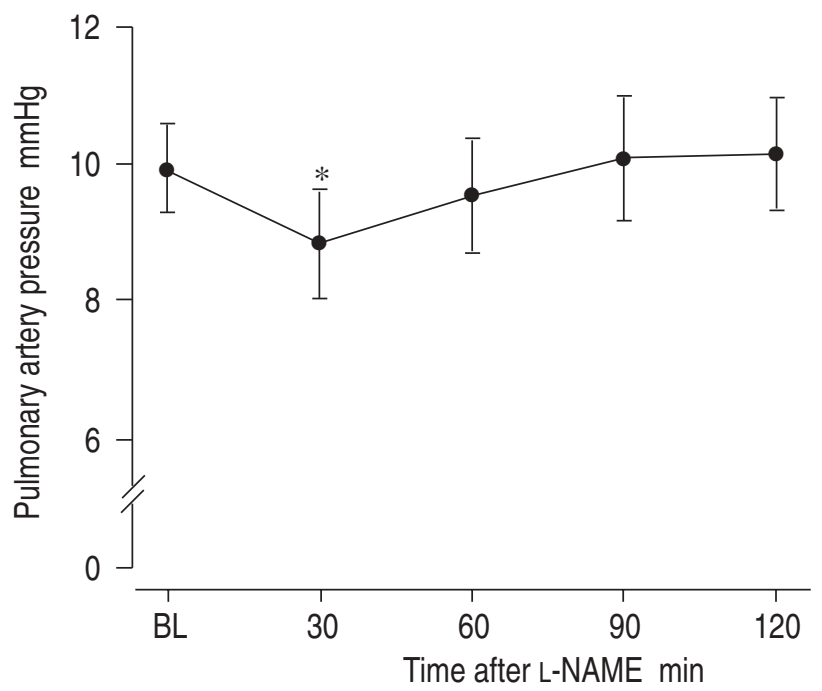

Fig. 3. - Pulmonary artery pressure at baseline (BL) and after nebulized $N^{\mathrm{G}}$-nitro-L-arginine methyl ester (L-NAME). Values are mean \pm SEM. $*: \mathrm{p}<0.05$ compared with BL.
An interesting finding of the present study was the lack of effect of nebulized L-NAME on pulmonary haemodynamics. Since intravenously administered L-NAME and other NOS inhibitors significantly increase both systemic and pulmonary arterial pressures $[31,35]$, there was some concern that its local administration in the lung could alter the vascular tone, thereby inducing pulmonary hypertension. This question was addressed in a subset of patients and this was found not to be the case. Nebulized L-NAME did not alter pulmonary artery pressure or cardiac output. Therefore, nebulized L-NAME at the currently employed dosage exerts no detrimental effect on pulmonary circulation.

In summary, the results of this study show that, in patients with mild-to-moderate asthma, there is no correlation between the basal concentration of exhaled nitric oxide and the underlying gas-exchange abnormalities and that the local inhibition of nitric oxide synthesis with nebulized $N^{\mathrm{G}}$-nitro-L-arginine methyl ester does not modify ventilation-perfusion distributions. The results indicate that gas-exchange impairment in clinically stable asthma does not appear to be related to an increased synthesis of nitric oxide in the airways.

Acknowledgements: The authors thank the technical staff of the Pulmonary Function Laboratory of the Hospital Clínic for their collaboration.

\section{References}

1. Rodriguez-Roisin R, Ferrer A, Navajas D, Agustí AGN, Wagner PD, Roca J. Ventilation-perfusion mismatch after methacholine challenge in patients with mild bronchial asthma. Am Rev Respir Dis 1991; 144: 88-94.

2. Roca J, Ramis LI, Rodriguez-Roisin R, Ballester E, Montserrat JM, Wagner PD. Serial relationships between $V^{\prime} \mathrm{A} / Q^{\prime}$ inequality and spirometry in acute severe asthma requiring hospitalization. Am Rev Respir Dis 1988; 137: 605-612.

3. Wagner PD, Hedenstierna G, Rodriguez-Roisin R. Gas exchange, expiratory flow obstruction and the clinical spectrum of asthma. Eur Respir J 1996; 9: 1278-1282.

4. Kobzik L, Brendt DS, Lowenstein CJ, et al. Nitric oxide synthase in human and rat lung: immunocytochemical and histochemical localization. Am J Respir Cell Mol Biol 1993; 9: 371-377.

5. Barnes PJ, Belvisi MG. Nitric oxide and lung disease. Thorax 1993; 48: 1034-1043.

6. Alving K, Weitzberg E, Lundberg JM. Increased amount of nitric oxide in exhaled air of asthmatics. Eur Respir $J$ 1993; 6: 1368-1370.

7. Persson MG, Zetterström O, Argenius V, Ihre E, Gustafsson LE. Single-breath nitric oxide measurements in asthmatic patients and smokers. Lancet 1994; 343: 146-147.

8. Kharitonov SA, Yates D, Robbins RA, Logan-Sinclair R, Shinebourne EA, Barnes PJ. Increased nitric oxide in exhaled air of asthmatic patients. Lancet 1994; 343: 133-135.

9. Yates DH, Kharitonov SA, Thomas PS, Barnes PJ. Endogenous nitric oxide is decreased in asthmatic patients by an inhibitor of inducible nitric oxide synthase. Am J Respir Crit Care Med 1996; 154: 247-250.

10. Barnes PJ. NO or not NO in asthma. Thorax 1996; 51: 218-220.

11. Högman MM, Frostell CG, Hedenström H, Hedenstierna 
G. Inhalation of nitric oxide modulates adult human bronchial tone. Am Rev Respir Dis 1993; 148: 1474-1478.

12. de Gow HWFM, Grünberg K, Schot R, Kroes ACM, Dick EC, Sterk PJ. Relationship between exhaled nitric oxide and airway hyperresponsiveness following experimental rhinovirus infection in asthmatic subjects. Eur Respir 1988; 11: 126-132.

13. Charan NB, Johnson SR, Lakshminarayan S, Thompson WH, Carvalho P. Nitric oxide and $\beta$-adrenergic agonist-induced bronchial arterial vasodilation. J Appl Physiol 1997; 82: 686-692.

14. Frostell CG, Blomqvist H, Hedenstierna G, Lundberg J, Zapoi WM. Inhaled nitric oxide selectively reverses human hypoxic pulmonary vasoconstriction without causing systemic vasodilation. Anesthesiology 1993; 78: 427-435.

15. Rodriguez-Roisin R, Roca J. Contribution of multiple inert gas elimination technique to pulmonary medicine 3: bronchial asthma. Thorax 1994; 49: 1027-1033.

16. Barberà JA, Roger N, Roca J, Rovira I, Higenbottam TW, Rodriguez-Roisin R. Worsening of pulmonary gas exchange with nitric oxide inhalation in chronic obstructive pulmonary disease. Lancet 1996; 347: 436-440.

17. Yates DH, Kharitonov SA, Robbins RA, Thomas PS, Barnes PJ. Effect of a nitric oxide synthase inhibitor and a glucocorticosteroid on exhaled nitric oxide. Am J Respir Crit Care Med 1995; 152: 892-896.

18. Gómez FP, Martínez-Pallì G, Barberà JA, Roca J, Rodríguez-Roisin R. Medicíon de óxido nítrico exhalado en sujetos sanos. Med Clin (Barc) 1998; 111: 1-5.

19. Cardús J, Burgos F, Diaz O, et al. Increase in pulmonary ventilation-perfusion inequality with age in healthy individuals. Am J Respir Crit Care Med 1997; 156: 648-653.

20. Farré R, Peslin R, Rotger M, Navajas D. Human lung impedance from spontaneous breathing frequencies to 32 Hz. J Appl Physiol 1994; 76: 1176-1183.

21. Roca J, Wagner PD. Contribution of multiple inert gas elimination technique to pulmonary medicine - 1: principles and information content of the multiple inert gas elimination technique. Thorax 1994; 49: 815-824.

22. Kharitonov SA, Alving K, Barnes PJ. Exhaled and nasal nitric oxide measurements: recommendations. Eur Respir $J$ 1997; 10: 1683-1693.

23. Kharitonov SA, Wells AU, O'Connor BJ, et al. Elevated levels of exhaled nitric oxide in bronchiectasis. Am J Respir Crit Care Med 1995; 151: 1889-1893.
24. Kharitonov SA, O'Connor BJ, Evans DJ, Barnes PJ. Allergen-induced late asthmatic reactions are associated with elevation of exhaled nitric oxide. Am J Respir Crit Care Med 1995; 151: 1894-1899.

25. Massaro AF, Gaston B, Kita D, Fanta C, Stamler JS, Drazen JM. Expired nitric oxide levels during treatment of acute asthma. Am J Respir Crit Care Med 1995; 152: 800-803.

26. Barnes PJ, Kharitonov SA. Exhaled nitric oxide: a new lung function test. Thorax 1996; 51: 233-237.

27. Ballester E, Roca J, Rodriguez-Roisin R, Agusti-Vidal A. Effect of nifedipine on arterial hypoxemia occurring after methacholine challenge in asthma. Thorax 1986; 41: 468-472.

28. Ballester E, Roca J, Ramis L, Wagner PD, RodriguezRoisin R. Pulmonary gas exchange in severe chronic asthma. Response to $100 \%$ oxygen and salbutamol. $A m$ Rev Respir Dis 1990; 141: 558-562.

29. Greenberg B, Kishiyama S. Endothelium-dependent and -independent responses to severe hypoxia in rat pulmonary artery. Am J Physiol 1993; 265: H1712-H1720.

30. Teng GQ, Barer GR. In vitro responses of lung arteries to acute hypoxia after NO synthase blockade or chronic hypoxia. J Appl Physiol 1995; 79: 763-770.

31. Putensen C, Räsänen J, Downs JB. Effect of endogenous and inhaled nitric oxide on the ventilation-perfusion relationships in oleic-acid lung injury. Am J Respir Crit Care Med 1994; 150: 330-336.

32. Sprague RS, Thiemermann C, Vane RJ. Endogenous endothelium-derived relaxing factor opposes hypoxic pulmonary vasoconstriction and supports blood flow to hypoxic alveoli in anesthetized rabbits. Proc Natl Acad Sci USA 1992; 89: 8711-8715.

33. Ricciardolo FL, Geppetti P, Mistretta A, et al. Randomized double-blind placebo controlled study of the effect of inhibition of nitric oxide synthesis in bradykinin-induced asthma. Lancet 1996; 348: 374-377.

34. Brain JD, Blanchard JD. Deposition and fate of inhaled pharmacological aerosols. In: Spector SL, ed. Provocation Testing in Clinical Practice. New York, Marcel Dekker, 1995; pp. 157-214.

35. Persson MG, Gustafsson LE, Wiklund NP, Moncada S, Hedqvist P. Endogenous nitric oxide as a probable modulator of pulmonary circulation and hypoxic pressor response in vivo. Acta Physiol Scand 1990; 140: 449-457. 